\title{
Workplace Phobia, Workplace Problems, and Work Ability among Primary Care Patients with Chronic Mental Disorders
}

\author{
Beate Muschalla, DPhil, and Michael Linden, MD
}

Purpose: Work-related anxieties are frequent and have a negative effect on the occupational performance of patients and absence due to sickness. Most important is workplace phobia, that is, panic when approaching or even thinking of the workplace. This study is the first to estimate the prevalence of workplace phobia among primary care patients suffering from chronic mental disorders and to describe which illness-related or workplace-specific context factors are associated with workplace phobia.

Methods: A convenience sample of 288 primary care patients with chronic mental disorders $(\mathbf{7 0 \%}$ women) seen by 40 primary care clinicians in Germany were assessed using a standardized diagnostic interview about mental disorders and workplace problems. Workplace phobia was assessed by the Workplace Phobia Scale and a structured Diagnostic and Statical Manual of Mental Disorders-based diagnostic interview. In addition, capacity and participation restrictions, illness severity, and sick leave were assessed.

Results: Workplace phobia was found in $10 \%$ of patients with chronic mental disorders, that is, approximately about 3\% of all general practice patients. Patients with workplace phobia had longer durations of sick leave than patients without workplace phobia and were impaired to a higher degree in work-relevant capacities. They also had a higher degree of restrictions in participation in other areas of life.

Conclusions: Workplace phobia seems to be a frequent problem in primary care. It may behoove primary care clinicians to consider workplace-related anxiety, including phobia, particularly when patients ask for a work excuse for nonspecific somatic complaints. (J Am Board Fam Med 2014;27: 486-494.)

Keywords: Anxiety, Mental Health, Sick Leave, Workplace

About $30 \%$ of the general population and of general practice patients suffer from mental disorders. ${ }^{1-3}$ Mental health disorders are costly for society, in part because of mental health-related problems at work. ${ }^{4-9}$ The average annual per capita

This article was externally peer reviewed.

Submitted 5 December 2013; revised 31 March 2014; accepted 4 April 2014.

From the Department of Work and Organizational Psychology, University of Potsdam, Germany (BM); Psychosomatic Rehabilitation Research Group, Charité University of Medicine, Berlin, Germany (BM, ML); and the Department of Behavioral Medicine, Rehabilitation Center Seehof, Teltow, Germany (ML).

Funding: This research was financially supported by the German Pension Fund.

Conflict of interest: none declared.

Corresponding author: B. Muschalla, DPhil, Psychosomatic Rehabilitation Research Group, Rehabilitation Center Seehof, Lichterfelder Allee 55, 14513 Teltow, Germany (E-mail: beate.muschalla@gmx.de). costs of an anxiety disorder in 2003 were $\$ 4934$ (health service uptake, patients' out-of-pocket costs, production losses). ${ }^{10}$ In this respect, workplace-related anxieties-especially workplace phobia-are of special interest because they are directly related to increased sick leave, job loss, or early retirement. ${ }^{11}$ Despite its clinical and societal relevance, workplace phobia is under-recognized and needs further research. ${ }^{11-13}$ Workplace phobia is characterized by a specific phobic anxiety reaction with emotional arousal and avoidance behavior when thinking of or being confronted with the workplace. ${ }^{11-14}$ Research shows that workplace-related anxieties and workplace phobia can occur within the frame of a common mental disorder and, in some cases, even as a standalone disorder. ${ }^{15}$ Referring to international diagnostic manuals, workplace phobia can be coded as "other phobic 
disorder" according to the International Classifications of Diseases, 10th Revision, ${ }^{16}$ category F40.8, or as 300.29, "specific phobia," according to the Diagnostic and Statistical Manual of Mental Disorders $I V$ (DSM-IV) ${ }^{17}$ without the criterion of perceived senselessness of the anxiety. Workplace phobia thus can be a kind of pathologic real angst, ${ }^{11}$ which means that patients with workplace phobia may be accurate in their perception that there are problems or dangers at their workplace, such as requirements to achieve, superiors, aggressive clients/students/ patients, team conflicts with colleagues, toxic substances, etc. Nevertheless, workplace phobic anxiety is clinically significant because the anxiety and avoidance reactions lead to problems at work, sick leave, or loss of the job-and therefore broader negative consequences for the person's professional biography. Workplace phobia can appear as an additional syndrome beside "general" non-work-associated mental disorders. ${ }^{11,18}$ People with workplace phobia have been found to react with physiologic arousal when imagining the workplace, whereas people without workplace phobia do not. ${ }^{12}$ Of patients with mental disorders receiving psychosomatic rehabilitation, $60 \%$ suffer from different forms of workplace-related anxieties, and 17\% suffer from workplace phobia. ${ }^{11,14}$ Among employees presently working who were not receiving treatment because of mental disorders and who showed no exaggerated general anxiety, about $5 \%$ reported tendencies of workplace avoidance due to workplace-related anxiety. ${ }^{19}$

If patients want to avoid the workplace because of work-related anxiety, the only way to do this without legal problems or financial losses is through a sick leave certificate. Since physicians in general practice are in control of sick leave certification, ${ }^{8}$ patients with workplace phobia regularly ask for their help. In the case of workplace-related anxieties, however, sick leave is a form of avoidance behavior and negative reinforcement ${ }^{20}$ for anxiety and can lead to an increase of workplace-related anxiety. Although to date there is no evidencebased approach to treating "workplace phobia," primary care clinicians might consider the possibility that workplace-related anxieties and workplace phobia may be the reason for demanding an excuse from work. Thus, sick leave certification alone cannot be the solution, but specific anxiety- and workrelated therapeutic approaches are needed. ${ }^{11}$ With regard to workplace-related anxieties, it is difficult to conduct exposition therapy directly at the workplace because of its inability to be controlled. Furthermore, it cannot be done anonymously, like in vivo exposition exercises in a tube. Evaluated therapy techniques must be adopted when using them with direction toward the workplace. This can be done with in sensu workplace exposition or exposition in training situations. Including work-directed aspects in treatment thus might be useful. ${ }^{21}$

In sum, knowledge about workplace phobia and its clinical character should be essential for primary care clinicians, since they are the first to be contacted by patients with workplace phobia when they request an excuse from work.

\section{Objectives}

Workplace phobia is a frequent problem, especially in patients with chronic mental disorders who are seen in psychosomatic rehabilitation settings and outpatient primary care. Chronic mental disorders and workplace problems are associated with sick leave and participation disorders and require treatment throughout the life span, that is, they affect the primary care setting. Therefore we chose the setting of primary care for this investigation. The objective of this study was to estimate the prevalence of workplace phobia among primary care patients suffering from chronic mental disorders and to describe which illness-related or workplace-specific context factors are associated with workplace phobia.

\section{Methods}

\section{Patient Recruitment}

Invitations to participate in the study were sent to 300 randomly selected primary care clinicians in Berlin, and 40 who replied with interest to participate were included. These participating physicians can be considered "prototypically representative" of clinicians who are interested in the treatment of mental disorders and are dedicated professionals. Patients aged 18 to 60 years were contacted personally by study psychologists in the waiting rooms of their primary care clinician's office. They were asked to fill in a short screening questionnaire including questions on general well-being (WHO-Five Well-being Index $\left.[\mathrm{WHO}-5]^{22}\right)$, a rating of illnessrelated participation disorders (Self-rating Index for the Measurement of Restrictions in Participation $[\mathrm{IMET}]^{23,24}$ ), and questions about whether the person suffers from a chronic mental health condition ${ }^{2}$ (Table 
Table 1. Inclusion Criteria for Patients with Chronic Mental Disorders Who Underwent Medical Assessment $^{2}$

- Age 18 to 60 years

- Answering the following 2 questions with "yes": Do you think that you are suffering at present from health problems that are not only somatic but also psychological in nature?

If there are psychological problems, have they existed for more than 6 months? (criterion of chronicity)

- A score of 0 or 1 on at least 1 item or a score of 2 on at least 3 items of the WHO-Five Well-being Index (a 22item self-rating questionnaire)

- An average score of 4 or a score of 5 on at least 1 item on the self-rating questionnaire of illness-related participation disorders across different domains of daily life (IMET) ${ }^{23,24}$

1). Those patients who reported suffering from chronic mental health problems and participation disorders according to the IMET (Table 1) were invited to participate in a thorough medical assessment done by a psychosomatically trained study physician. The assessment was done in the primary care clinician's office. Participants gave written informed consent. The medical assessment included examination of the somatomedical status and current therapy status and standardized diagnostic interviews about mental disorders (the Mini International Neuropsychiatric Interview $[\mathrm{MINT}]^{25}$ and the Work Anxiety Interview ${ }^{15}$ ) and capacity disorders (Observer-rating of Disorders in Capacities and Participation due to Mental Disorders [Mini-ICFAPP]). ${ }^{26,27}$ The study was approved by the human subjects review board of the German Pension Fund.

\section{Instruments}

Current mental disorders were diagnosed by the research physician using the MINI, ${ }^{25,28}$ an internationally validated and broadly used structured instrument to make research diagnoses for the full range of mental disorders according to DSM-IV. The interview has good test-retest reliability $(\kappa=$ $0.76-0.93)$ and sensitivity and specificity $(0.70$ and 0.85 , respectively). ${ }^{28}$ To identify patients with workplace phobic anxiety, a validated interview module (interrater reliability, $\kappa=0.89^{11,29}$ ) about "workplace phobia" was added. Accordingly, patients with a diagnosis of workplace phobia fulfilled the criteria that they suffer from panic-like anxiety when being at or simply thinking of their workplace, they try to avoid the workplace whenever possible, and because of the anxiety symptoms have impaired functioning when at the workplace.
Because mental disorders are characterized by capacity restrictions, capacity and participation impairment were assessed by the research physician using the Mini-ICF-APP, ${ }^{26,27}$ an internationally evaluated observer rating instrument giving a selection of capacities in reference to the World Health Organization's International Classification of Functioning, Disability, and Health, ${ }^{30}$ building on definitions of the Groningen Social Disabilities Schedule II. ${ }^{31}$ The Mini-ICF-APP includes the following capacities: (1) adherence to regulations, (2) planning and structuring of tasks, (3) flexibility, (4) professional competency, (5) judgements, (6) endurance, (7) assertiveness, (8) contact with others, (9) group integration (10) intimate relationships, (11) spontaneous activities, (12) self-care, and (13) mobility. Each dimension is rated on a 5-point Likert-scale $(0=$ no impairment, $1=$ mild impairment without problems in the environmental context, 2 = moderate disability causing problems in the environment, $3=$ severe disability causing problems and necessitating assistance, $4=$ total disability and exemption from all respective duties). Anchor definitions for each item are provided in a rating manual. Rating uses all available information, including the individual's self-report, case record, and observation from the interview situation. Interrater reliability $(r)$ was between 0.70 and $0.92 .{ }^{26}$ Cronbach $\alpha$ was 0.86 in this study.

In addition, participation disorders in different dimensions of life were measured. The Index for the Measurement of Restrictions in Participation $(\mathrm{IMEP})^{2}$ is an observer-based rating instrument measuring illness-related restrictions in participation. It is designed parallel to the self-rated IMET $^{23,24}$ The IMEP presents 10 areas of life: (1) activities of daily living (eg, washing, eating); (2) activities at home (eg, housework, gardening); (3) activities outside the home (eg, shopping, driving around); (4) duties (eg, cleaning up, care of others); (5) recreational activities (eg, sports, leisure time); (6) social activities (eg, meeting friends, going to the theater); (7) close relations (eg, partner, family); (8) sexual life (quantity and quality); (9) coping with stress; and (10) work. In response to the statement, "In the following area of life the patient is impaired because of his/her present state of health," the rater is asked to rate each item on a visual analog scale ranging from 0 (no impairment) to 10 (no activity possible any more). The rating was done by the research physician. Cronbach $\alpha$ was 0.88 for all 
items in this study. Therefore the global mean score can be used as a general indicator of the degree of impairment.

The Workplace Phobia Screening (WPS) ${ }^{11,32}$ is a self-rating scale for measuring workplace phobic anxiety and workplace avoidance behavior. It contains 13 items. It has been extracted from the Job Anxiety Scale, ${ }^{33,34}$ which covers further workplace anxiety dimensions apart from phobia. The WPS is presented to patients as "questionnaire on workplace problems" that examines "behavior, thoughts, and feelings that can occur in relation to the workplace." Cronbach $\alpha$ was 0.94 for all these items in this study. The scale was validated in previous studies with different non-work-related anxiety and general psychopathology questionnaires. ${ }^{34,35}$

The WHO-5 rating was used as an indicator of the amount of mental symptom load present. The WHO-5 well-being rating ${ }^{22}$ has 5 items and asks whether the patient felt well, relaxed, active, and full of interest for life during the past 2 weeks. The rating is done on a 6-step scale, from "I feel like this all the time" (score of 5) to "I never feel like this" (score of 0). The WHO-5 is an internationally known and validated screening for mental disorders. ${ }^{36-38}$

Because mental disorders and workplace-related anxiety can come along with somatic complaints, the somatic health status had to be measured. Using the Burvill rating scale for quantification of physical illness, ${ }^{39}$ acute and chronic somatic morbidity was measured by the number of body systems that were affected by acute and/or chronic somatic illness and the severity of the illnesses. The Burvill rating includes 10 body systems: cardiac system, metabolic system, lungs, urinary tract, gastrointestinal system, blood, senses, musculoskeletal system, nervous system, mental disorders. The rating for all body systems was from "no complaints" (score of 0 ) to "heaviest complaints" (score of 3). The mean score for all body systems serves as a general indicator for the degree of overall illness severity and was used in this study. The interrater reliability as well as the retest reliability were $r=0.93 .^{39}$

Patients were asked to give information on their workplace status (eg, presently employed or not employed) and whether they had problems at their present or last workplace. If there were problems, these were specified (qualitative or quantitative overload, bullying or social conflicts, periods of absence, problems with workplace structure or restructuring).

\section{Results}

A total of 1629 patients were contacted; according to self-report, 559 (34.3\%) fulfilled the inclusion criteria for a chronic mental condition. This rate is almost similar to the rate of mental disorders among the general population and patients in primary care. ${ }^{1,2}$ Of these 559, 307 agreed to participate in the intensive medical assessment, and 288 could be included in the final analysis with full data.

Of the final sample (patients with chronic mental disorders), $70.4 \%$ were females. This preponderance of women is typical for mental disorders. ${ }^{40}$ According to the DSM-IV diagnostic algorithms of the MINI, ${ }^{25,28} 40.8 \%$ of patients suffered from a depressive episode or dysthymia, 30.4\% from agoraphobia and/or panic disorder, $18 \%$ from adjustment disorders, $11.8 \%$ from alcohol or drug abuse, $8.5 \%$ from generalized anxiety disorder, and $6.5 \%$ from personality disorders; $65.5 \%$ said that they had a workplace at present, $27.7 \%$ were on sick leave, $8.6 \%$ had applied for a disability pension.

From among the 288 patients, $10.1 \%(n=29)$ were suffering from workplace phobia according to the standardized diagnostic interview, that is, panic and avoidance behavior when coming near or speaking about the workplace. Estimating the prevalence of workplace phobia among all general practice patients, given that about one third have chronic mental problems, then the overall prevalence is $3 \%$.

Patients with workplace phobia were on sick leave for 17.07 weeks (standard deviation, 19.7 weeks) during the past 12 months, compared with 8.62 weeks (standard deviation 13.9 weeks $(P=$ .032 ) weeks in other patients with mental problems but without workplace phobia. Of the patients with workplace phobia, $62.1 \%(\mathrm{n}=18)$ were on sick leave, and $16.4 \%(\mathrm{n}=18)$ of 110 patients who were on sick leave had a workplace phobia. Only 17 of 29 patients with workplace phobia currently had a workplace. Patients with workplace phobia attributed their health problems much more to the workplace than do patients without workplace phobia (Tables 2 and 3).

Patients with workplace phobia did not report more structural problems at their workplace or job insecurity. However, workplace phobic patients more often reported being overtaxed at work because of the content or amount of work $(P=.000)$. They also tend to perceive conflicts and bullying more often $(P=.105)$. 
Table 2. Comparison of Characteristics of Patients with and without Workplace Phobia $(\mathrm{n}=288)$

\begin{tabular}{|c|c|c|c|c|}
\hline Characteristics & $\begin{array}{c}\text { Patients with } \\
\text { Workplace } \\
\text { Phobia }(\mathrm{n}=29)\end{array}$ & $\begin{array}{c}\text { Patients without } \\
\text { Workplace } \\
\text { Phobia }(\mathrm{n}=259)\end{array}$ & $\begin{array}{c}P \\
\text { Value* }\end{array}$ & Cohen's d \\
\hline Age (years) & $43.66(8.9)$ & $42.91(10.9)$ & .721 & 0.07 \\
\hline Time in psychiatric treatment & $5.52(12.6)$ & $9.45(36.5)$ & .565 & 0.11 \\
\hline Time in psychotherapeutic treatment & $7.45(13.8)$ & $5.46(14.3)$ & .476 & 0.14 \\
\hline Amount of psychosomatic rehabilitation in the past 5 years (weeks) & $0.93(2.4)$ & $0.58(2.0)$ & .380 & 0.17 \\
\hline Patients with health problems attributed to the work situation (\%) & $58.6(28.6)$ & $26.8(31.9)$ & $.000^{\dagger}$ & 1.01 \\
\hline Duration of sick leave in the past 12 months (weeks) & $17.07(19.7)$ & $8.62(13.9)$ & $.032^{\ddagger}$ & 0.63 \\
\hline Present duration of sick leave (weeks) & $13.66(23.0)$ & $6.58(20.9)$ & .122 & 0.34 \\
\hline \multicolumn{5}{|l|}{ Self-rating of mental and somatic symptom load } \\
\hline Workplace Phobia Screening score & $2.79(0.74)$ & $0.88(0.89)$ & $.000^{\dagger}$ & 2.19 \\
\hline WHO-5 score & $1.4(0.9)$ & $1.48(0.8)$ & .601 & 0.10 \\
\hline \multicolumn{5}{|l|}{ Burvill rating } \\
\hline Acute somatic multimorbidity & $0.49(0.4)$ & $0.41(0.4)$ & .277 & 0.20 \\
\hline Chronic somatic multimorbidity & $0.86(0.56)$ & $0.65(0.55)$ & .069 & 0.38 \\
\hline
\end{tabular}

Data are means (standard deviations).

${ }^{*}$ 2-Tailed $t$ test for independent samples.

${ }^{\dagger} P<.01$.

${ }^{\ddagger} P<.05$.

Patients with workplace phobia were significantly more affected by specific workplace-related anxiety symptoms and avoidance behavior (per the WPS) than patients without workplace phobia. There were no differences between patients with and without workplace phobia with respect to general workplace-independent wellbeing (per the WHO-5). Patients with workplace phobia tended to report more frequently multiple somatic complaints than patients without workplace phobia (chronic multimorbidity; $P=.069$ ).

Workplace phobic patients showed higher degrees of impairment on the Mini-ICF-APP capacities planning and structuring of tasks, flexi- bility, judgment, and - with marginal significancecontacts with others and mobility. They are not as impaired in capacities needed for spontaneous activities, family and intimate relationships, or selfcare (Table 4). According to the IMEP there are comparably stronger restrictions in participation in activities outside the home activities and in the domain of work, as well as in close relations and daily duties.

\section{Discussion}

To our knowledge, this study is the first to explore workplace phobia in general practice patients. In ur-

Table 3. Prevalence of Problems in the Workplace in Patients with a Workplace and with or without Workplace Phobia

\begin{tabular}{lccc}
\hline Workplace Problems & $\begin{array}{c}\text { Patients with a Workplace and } \\
\text { Workplace Phobia (n = 17) }\end{array}$ & $\begin{array}{c}\text { Patients with a Workplace but without } \\
\text { Workplace Phobia (n }=180)\end{array}$ & $P$ Value* \\
\hline Problems are present & 58.6 & 38.2 & $.000^{\dagger}$ \\
Long or frequent sick leave absence & 35.3 & 24.0 & .304 \\
Mobbing and conflicts & 29.4 & 14.4 & .105 \\
Overtaxation with amount of work & 76.5 & 29.9 & $.000^{\dagger}$ \\
Overtaxation with work content & 47.1 & 12.0 & $.000^{\dagger}$ \\
Structural/environmental problems & 29.4 & 21.0 & .421 \\
Endangered in the workplace & 17.6 & 13.8 & .662 \\
\hline
\end{tabular}

Data are percentages.

${ }^{*} \chi^{2}$ Test.

${ }^{\dagger} P<.01$. 
Table 4. Capacity and Participation Disorders in Patients with and without Workplace Phobia

\begin{tabular}{|c|c|c|c|c|}
\hline Capacity Disorders & $\begin{array}{l}\text { Patients with } \\
\text { Workplace Phobia } \\
\quad(\mathrm{n}=29)\end{array}$ & $\begin{array}{l}\text { Patients without } \\
\text { Workplace Phobia } \\
\quad(\mathrm{n}=259)\end{array}$ & $P$ Value* & Cohen's d \\
\hline \multicolumn{5}{|l|}{ Rated by physician according using Mini-ICF-APP } \\
\hline Adherence to regulations & $0.73(0.78)$ & $0.42(0.73)$ & 0.254 & 0.42 \\
\hline Planning and structuring of tasks & $0.93(0.84)$ & $0.61(0.8)$ & $0.045^{\dagger}$ & 0.4 \\
\hline Flexibility & $1.45(0.91)$ & $0.92(0.97)$ & $0.005^{\dagger}$ & 0.55 \\
\hline Competency & $0.48(0.8)$ & $0.24(0.6)$ & 0.110 & 0.39 \\
\hline Endurance & $1.17(1.0)$ & $0.92(0.9)$ & 0.202 & 0.28 \\
\hline Assertiveness & $1.03(0.9)$ & $0.79(0.88)$ & 0.160 & 0.27 \\
\hline Contact with others & $1.1(1.0)$ & $0.71(0.8)$ & 0.052 & 0.48 \\
\hline Group integration & $0.76(0.87)$ & $0.59(0.83)$ & 0.306 & 0.20 \\
\hline Intimate relationships & $0.93(1.0)$ & $0.79(0.9)$ & 0.453 & 0.15 \\
\hline Nonwork activities & $1.28(0.92)$ & $1.17(0.87)$ & 0.553 & 0.13 \\
\hline Self-care & $0.1(0.4)$ & $0.05(0.3)$ & 0.377 & 0.16 \\
\hline Mobility & $0.79(0.97)$ & $0.48(0.87)$ & 0.072 & 0.35 \\
\hline Competence to judge and decide & $1.38(0.86)$ & $0.88(0.92)$ & $0.005^{\dagger}$ & 0.55 \\
\hline \multicolumn{5}{|l|}{ Rated by Physician Using IMEP } \\
\hline \multicolumn{5}{|l|}{$\begin{array}{l}\text { Degree to which there are participation limitations } \\
\text { due to illness in the following domains of life }\end{array}$} \\
\hline $\begin{array}{l}\text { Activities of daily living (washing, dressing, eating, } \\
\text { moving in one's home) }\end{array}$ & $1.2(2.0)$ & $1.04(1.9)$ & 0.651 & 0.08 \\
\hline $\begin{array}{l}\text { Activities at home (work in house and garden, } \\
\text { family care) }\end{array}$ & $2.59(2.5)$ & $2.15(2.4)$ & 0.356 & 0.18 \\
\hline $\begin{array}{l}\text { Activities outside the house (hand to mouth buying, } \\
\text { moving in one's hometown) }\end{array}$ & $3.28(2.2)$ & $2.46(2.3)$ & 0.074 & 0.36 \\
\hline $\begin{array}{l}\text { Duties (cleaning up, adherence to dates, doing } \\
\text { shopping outside one's house) }\end{array}$ & $4.83(2.0)$ & $3.44(2.3)$ & $0.002^{\dagger}$ & 0.61 \\
\hline $\begin{array}{l}\text { Recreational activities (hobbies, relaxation, enjoying } \\
\text { time spent off work) }\end{array}$ & $4.34(2.6)$ & $4.21(2.1)$ & 0.753 & 0.06 \\
\hline $\begin{array}{l}\text { Social activities (meeting friends, talking with } \\
\text { neighbors, going to parties) }\end{array}$ & $4.28(2.0)$ & $3.8(2.16)$ & 0.258 & 0.22 \\
\hline Close relations (being with one's partner or family) & $4.31(2.12)$ & $3.39(2.5)$ & 0.054 & 0.37 \\
\hline Sexual life (appropriate quality and quantity) & $4.14(3.3)$ & $3.61(3.0)$ & 0.381 & 0.18 \\
\hline $\begin{array}{l}\text { Coping with stress (family conflicts, illness, financial } \\
\text { problems, unexpected life events) }\end{array}$ & $5.69(1.8)$ & $5.15(1.9)$ & 0.148 & 0.29 \\
\hline $\begin{array}{l}\text { Work (adequately fulfilling one's duties at work and } \\
\text { following further training) }\end{array}$ & $6.17(2.3)$ & $5.2(2.3)$ & $0.033^{\dagger}$ & 0.42 \\
\hline
\end{tabular}

Data are means (standard deviations).

*2-Tailed $t$ test for independent samples.

${ }^{\dagger} P<.05$.

IMEP, Index for the Measurement of Restrictions in Participation; Mini-ICF-APP, Observer-rating of Disorders in Capacities and Participation due to Mental Disorders.

ban German general practice at least 2\% to $3 \%$ of all patients and $10 \%$ of those with chronic mental disorders suffer from workplace phobia. This rate is only little lower than the rate found among psychosomatic inpatients (17\%) and double that found in nonclinical samples of employees. ${ }^{19}$ This indicates the minimum rate of work-related anxieties because there are further work-related types of anxiety that do not always develop into workplace phobia but can still be disabling in other ways. ${ }^{14,29}$ Examples are work-related hypochondriasis, work-related generalized anxiety, work-related feelings of insufficiency, or work-related social anxiety. Among other comparable samples of patients with chronic mental disorders who are receiving psychosomatic rehabilitation, about $60 \%$ suffer from any of these workplace-related anxieties in addition to their basic mental disorder. ${ }^{15}$ Therefore, work-related anxieties might be expected to occur regularly and pose an almost daily problem for primary care clinicians. 


\section{Strengths and Limitations}

A limitation of the study is that it is cross-sectional, and therefore no data over the course of anxiety are available. Another limitation is that there are only few patients with workplace phobia. However, this prevalence can realistically be found in routine primary care. The strength of this study is that diagnostic, observer-based assessments were conducted by a research physician and based on a thorough medical assessment using validated instruments and evaluated standardized interviews for mental disorders and about general and workplace phobia in particular. ${ }^{11,15,28}$

\section{Comparison with the Existing Literature}

The data from this study add to the previous knowledge of workplace-related anxieties. They highlight that workplace-related anxieties, especially workplace phobia, are severe disorders because they are accompanied by severe burdens, including increased rates of sickness-related absence. ${ }^{11,29}$ Our data show that there is a higher rate of sick leave among workplace phobic patients, although the comparison group also suffered from chronic mental disorders. This can be explained by the fact that in workplace phobia the workplace is the anxiety-provoking stimulus and that one way of fighting anxiety is avoidance through sick leave. Long-term sick leave as a negative reinforcement can increase anxiety, which in consequence prolongs the duration of sick leave. Workplace phobics correspondingly attribute their health problems to the workplace more than others do. Therefore, demand for a sick leave certificate in otherwise unclear medical conditions can be seen as an indicator for possible workplace phobia, and physicians should aware that there might be side effects such as an increase in anxiety and long-term sick leave if they give in to the patient's request.

Overtaxation can be one factor in the development of workplace phobia because of limitations in capacities, as described in the World Health Organization's International Classification of Functioning, Disability, and Health. ${ }^{30}$ Patients with workplace phobia are especially impaired in those capacity dimensions that are most essential at the workplace, that is, capacities of planning and structuring, flexibility, competency to make judgements, the ability to be in contact with others, and mobility, which is necessary for getting to the workplace.

Interestingly, patients with workplace phobia report more problems at work in specific aspects:
There is more overtaxation because of "too much work" or "the wrong work duties" and more interactional problems. This is in line with other findings from psychosomatic patients, among whom social conflicts were also a main problem associated with workplace-related anxieties. ${ }^{41}$

Workplace-phobic patients also are more impaired in activities outside the home. An explanation is that patients with workplace phobia tend to avoid the surroundings of the workplace, which means that the disorder can generalize to agoraphobia. They may avoid the local supermarket because of the fear of meeting colleagues or superiors (and not, like an agoraphobic, because of fear of suffering a sudden panic attack and getting no help). There are also stronger impairments in close relationships among workplace-phobic patients. This indicates that workplace problems can also afflict the family and other areas of life.

Workplace-phobic anxiety can be distinguished from general psychological burden, as suggested by the results of the WHO-5. General well-being was the same in patients with and without workplace phobia, whereas workplace phobic anxiety, as measured by the WPS, was significantly higher among workplace phobics. This underlines that workplace anxiety is a special syndrome that can be delineated from other mental problems. Rather, it is typical that phobic patients feel well as long as they can avoid the anxiety-provoking stimulus, be it the subway or the workplace. The exception is that patients with workplace phobia more often report multiple somatic complaints; panic is typically experienced by patients as a somatic rather than psychological problem. This gives a warning that patients with workplace phobia contact the general practitioner often with somatic complaints, which can make it difficult to diagnose the real problem.

\section{Implications for Practice}

Work-related impairment is associated to a greater degree with workplace phobia than with general mental disorders or complaints. Workplace phobia is characterized by arousal and panic when approaching the workplace and relief by avoiding it. Workplace phobia can be a single problem but can also be associated with other mental disorders. Either way it complicates the course of illness (longterm sick leave, early retirement pension) and the treatment of such patients. Primary care clinicians should consider workplace phobia when patients 
present with unspecific somatic complaints, avoidance toward their workplace, and a request for an excuse for sick leave, since about $3 \%$ of patients and $10 \%$ of those with persisting mental problems suffer from this condition. A proper diagnosis ("workplace phobia") and the differentiation from other anxiety disorders ${ }^{42}$ is necessary for adequate communication between physicians and for specific and work-directed treatment. Primary care clinicians are the first to be contacted by patients. The real problem often is hidden behind other somatic complaints. Sick leave certificates can reinforce avoidance behavior. The diagnosis of workplace phobia can be made from exploration with, for example, the Work Anxiety Interview ${ }^{11,15}$ and by considering the patient's reaction when speaking directly about their workplace. In cases of workplace phobia, arousal ${ }^{12}$ and an avoidance tendency must be observed when the workplace is discussed. A decision about sick leave certification and therapy necessities (eg, work skills training, conflict management) requires additional exploration of the work duties and workplace conditions. Future research on treatment approaches for workplace-related anxieties and investigation of workplace-related anxieties in nonclinical samples, for example, in different workplace environments, must be done.

\section{References}

1. Wittchen HU, Jacobi F, Rehm J, et al. The size and burden of mental disorders and other disorders of the brain in Europe 2010. Eur Neuropsychopharmacol 2011;21:655-79.

2. Linden M, Muschalla B, Keßler U, Haverkamp L, Rath K. Reha in der Hausarztpraxis. Rehabedarfsfeststellung, -zugang, -steuerung, -koordinierung, -optimierung und -verstetigung bei psychischen Erkrankungen unter Mitwirkung niedergelassener Ärzte. Eine Untersuchung zum Stand und zu den Optimierungsmöglichkeiten durch ein Rehakonsil. Abschlussbericht zum Modellprojekt. Berlin: Deutsche Rentenversicherung Bund; 2012.

3. Linden M. Mental disorders in primary care. Adv Psychosom Med 2004;26:52-65.

4. Greenberg PE, Sisitsky T, Kessler RC, Finkelstein SN, Berndt ER, Davidson JR. The economic burden of anxiety disorders in the 1990s. J Clin Psychiat 1999;60:427-35.

5. Haslam C, Atkinson S, Brown SS, Haslam RA. Anxiety and depression in the workplace: effects on the individual and organisation (a focus group investigation). J Affect Disord 2005;88:209-15.

6. Haslam C, Atkinson S, Brown SS, Haslam RA. Perceptions of the impact of depression and anxiety and the medication for these conditions on safety in the workplace. Occup Environ Med 2005;62:538-45.

7. Langlieb AM, Kahn JP. How much does quality mental health care profit employers? J Occup Environ Med 2005;47:1099-109.

8. Nieuwenhuijsen K, Verbeek JH, de Boer AG, Blonk RW, van Dijk FJ. Predicting the duration of sickness absence for patients with common mental disorders in occupational health care. Scand J Work Environ Health 2006;32:67-74.

9. Wynne-Jones G, Mallen CD, Mottram S, Main CJ, Dunn KM. Identification of UK sickness certification rates, standardised for age and sex. $\mathrm{Br} \mathrm{J}$ Gen Pract 2009;59:510-6.

10. Smit F, Cuijpers P, Oostenbrink J, Batelaan N, de graaf R, Beekamn A. Costs of nine common mental disorders: implications for curative and preventive psychiatry. J Ment Health Policy Econ 2006;9:193200.

11. Muschalla B, Linden M. Workplace phobia: a first explorative study on its relation to established anxiety disorders, sick leave, and work-directed treatment. Psychol Health Med 2009;14:591-605.

12. Haines J, Williams CL, Carson JM. Workplace phobia: psychological and psychophysiological mechanisms. Int J Stress Manag 2002;9:129-45.

13. Smith ME. Work phobia and sickness leave certificates. Afr J Psychiatry 2009;12:249-52.

14. Muschalla B. Workplace-related anxieties and workplace phobia. A concept of domain-specific mental disorders [PhD thesis]. Potsdam, Germany: University of Potsdam; 2008.

15. Linden M, Muschalla B. Anxiety disorders and workplace-related anxieties. J Anxiety Disord 2007;21: 467-74.

16. World Health Organization (WHO). International statistical classification of diseases and related health problems, 10th revision. Geneva: WHO; 1992.

17. American Psychiatric Association (APA). Diagnostic and statistical manual of mental disorders IV. Washington, DC: APA; 1994.

18. Muschalla B. Workplace phobia. German J Psychiatry 2009;12:45-53.

19. Muschalla B, Heldmann M, Fay D. The meaning of job-anxiety in a working population. Occup Med 2013;63:415-21.

20. Skinner BF. Contingencies of reinforcement: a theoretical analysis. New York: Appleton CenturyCrofts; 1969.

21. Lagerveld SE, Blonk RW, Brenninkmeijer V, Wijngaards-de Meij L, Schaufeli WB. Work-focused treatment of common mental disorders and return to work: a comparative outcome study. J Occup Health Psychol 2012;17:220-34.

22. World Health Organization. WHO-5. Fragebogen zum Wohlbefinden. Frederiksborg, Denmark: WHO Collaborating Center for Mental Health, Psychiatric Research Unit, Frederiksborg General Hospital; 1998. 
23. Deck R, Mittag O, Hüppe A, Muche-Borowski C, Raspe H. Index zur Messung von Einschränkungen der Teilhabe (IMET) - Erste Ergebnisse eines ICForientierten Assessmentinstruments. Prax klin Verhaltensmed Rehabil 2007;76:113-7.

24. Muschalla B, Vilain M, Lawall C, Lewerenz M, Linden M. Participation restrictions at work indicate participation restrictions in other domains of live. Psychol Health Med 2012;17:95-104.

25. Sheehan D, Janavs J, Baker R, Knapp E, Sheehan KH, Sheehan M. Mini International Neuropsychiatric Interview (MINI). Tampa: University of South Florida; 1994.

26. Linden M, Baron S, Muschalla B. Mini-ICF-rating für psychische Störungen (Mini-ICF-APP). Ein Kurzinstrument zur Beurteilung von Fähigkeitsbzw. Kapazitätsstörungen bei psychischen Störungen. Göttingen: Hans Huber; 2009.

27. Molodynski A, Linden M, Juckel G, et al. The reliability, validity, and applicability of an English language version of the Mini-ICF-APP. Soc Psychiatry Epidemiol 2013;48:1347-54.

28. Sheehan D, Lecrubier Y, Sheehan H, et al. The Mini International Neuropsychiatric Interview: the development and validation of a structured diagnostic psychiatric interview for DSM-IV and ICD-10. J Clin Psychiatry 1998;59:22-33.

29. Linden M, Muschalla B, Glatz J, Herm K, Markova M, Dirks S. Abschlussbericht zum Forschungsprojekt Arbeitsplatzbezogene Ängste und Arbeitsplatzphobie bei Patienten in der psychosomatischen und kardiologischen Rehabilitation. Berlin: DRV Bund; 2009.

30. World Health Organization (WHO). International classification of functioning, disability and health (ICF). Geneva: WHO; 2001.

31. Wiersma D, DeJong A, Kraaijkamp HJM, Ormel J. The Groningen Social Disabilities Schedule. Manual and questionnaires, 2nd version. Groningen: University of Groningen, Department of Social Psychiatry, World Health Organization; 1990.
32. Muschalla B, Linden M. Die Arbeitsplatzphobieskala. Ein Screening-Instrument für die medizinische Rehabilitation. Ärztliche Psychotherapie 2008;3:258-62.

33. Linden M, Muschalla B, Olbrich D. Die Job-AngstSkala (JAS). Ein Fragebogen zur Erfassung arbeitsplatzbezogener Ängste. ZAO 2008;52:126-34.

34. Muschalla B, Linden M, Olbrich D. The relationship between job-anxiety and trait-anxiety-a differential diagnostic investigation with the Job-AnxietyScale and the State-Trait-Anxiety-Inventory. J Anxiety Disord 2010;24:366-71.

35. Muschalla B, Linden M. Specific job-anxiety in comparison to general psychosomatic symptoms at admission, discharge and six months after psychosomatic inpatient treatment. Psychopathology 2012; 45:167-73.

36. Saipanish R, Lotrakul M, Sumrithe S. Reliability and validity of the Thai version of the WHO-Five WellBeing Index in primary care patients. Psychiatry Clin Neurosci 2009;63:141-6.

37. Bonsignore M, Barkow K, Jessen F, Heun R. Validity of the five-item WHO Well-Being Index (WHO-5) in an elderly population. Eur Arch Psychiatry Clin Neurosci 2001;251:27-31.

38. Birket-Smith M, Rasmussen A. Screening for mental disorders in cardiology outpatients. Nord J Psychiatry 2008;62:147-50.

39. Burvill PW, Moery B, Hall WD. Quantification of physical illness in psychiatric research in the elderly. Int J Geriatr Psych 1990;5:161-70.

40. Klose M, Jacobi F. Can gender differences in the prevalence of mental disorders be explained by sociodemographic factors? Arch Womens Ment Health 2004;7: 133-48.

41. Muschalla B, Markova M, Linden M. Perceived jobanxiety and general psychosomatic symptom load and perceived social support-is there a relationship? Work 2010;37:29-39.

42. Roy-Byrne P, Veitengruber JP, Bystritsky A, et al. Brief intervention for anxiety in primary care patients. J Am Board Fam Med 2009;22:175-86. 